\title{
Atypical DNA methylation of genes encoding cysteine-rich peptides in Arabidopsis thaliana
}

\author{
Wanhui You ${ }^{1 \dagger}$, Agata Tyczewska ${ }^{1,4 \dagger}$, Matthew Spencer ${ }^{1}$, Lucia Daxinger ${ }^{1,5}$, Marc W Schmid ${ }^{2}$, Ueli Grossniklaus ${ }^{2}$, \\ Stacey A Simon ${ }^{3}$, Blake C Meyers ${ }^{3}$, Antonius JM Matzke ${ }^{1}$ and Marjori Matzke ${ }^{1 *}$
}

\begin{abstract}
Background: In plants, transposons and non-protein-coding repeats are epigenetically silenced by CG and non-CG methylation. This pattern of methylation is mediated in part by small RNAs and two specialized RNA polymerases, termed Pol IV and Pol V, in a process called RNA-directed DNA methylation. By contrast, many protein-coding genes transcribed by Pol II contain in their gene bodies exclusively CG methylation that is independent of small RNAs and Pol IV/Pol V activities. It is unclear how the different methylation machineries distinguish between transposons and genes. Here we report on a group of atypical genes that display in their coding region a transposon-like methylation pattern, which is associated with gene silencing in sporophytic tissues.

Results: We performed a methylation-sensitive amplification polymorphism analysis to search for targets of RNA-directed DNA methylation in Arabidopsis thaliana and identified several members of a gene family encoding cysteine-rich peptides (CRPs). In leaves, the CRP genes are silent and their coding regions contain dense, transposon-like methylation in CG, CHG and CHH contexts, which depends partly on the Pol IV/Pol V pathway and small RNAs. Methylation in the coding region is reduced, however, in the synergid cells of the female gametophyte, where the CRP genes are specifically expressed. Further demonstrating that expressed CRP genes lack gene body methylation, a CRP4-GFP fusion gene under the control of the constitutive $35 \mathrm{~S}$ promoter remains unmethylated in leaves and is transcribed to produce a translatable mRNA. By contrast, a CRP4-GFP fusion gene under the control of a CRP4 promoter fragment acquires CG and non-CG methylation in the CRP coding region in leaves similar to the silent endogenous CRP4 gene.

Conclusions: Unlike CG methylation in gene bodies, which does not dramatically affect Pol II transcription, combined CG and non-CG methylation in CRP coding regions is likely to contribute to gene silencing in leaves because loss of this methylation in synergid cells is associated with CRP gene expression. We discuss this unusual methylation pattern and its alteration in synergid cells as well as the possible retrogene origin and evolutionary significance of CRP genes that are methylated like transposons.
\end{abstract}

\section{Background}

Plants have evolved a complex transcriptional machinery for generating and using small RNAs that guide DNA cytosine methylation at homologous regions of the genome. Key components of the RNA-directed DNA methylation pathway include two functionally diversified RNA polymerase II (Pol II)-related RNA polymerases called Pol IV and Pol V [1]. Pol IV is needed to produce the small RNA trigger for methylation whereas Pol V acts downstream of

\footnotetext{
* Correspondence: marjori.matzke@gmi.oeaw.ac.at

${ }^{\dagger}$ Equal contributors

'Gregor Mendel Institute of Molecular Plant Biology, Austrian Academy of

Sciences, Vienna, Austria

Full list of author information is available at the end of the article
}

small RNA biogenesis to facilitate de novo methylation of genomic DNA at the small RNA-targeted site. Additional factors, including chromatin remodelers, putative transcription factors, and several novel, plant-specific proteins whose functions are not well understood, are required for Pol V function [1,2]. In a current model, Pol V synthesizes scaffold transcripts that interact with ARGONAUTE4bound small RNAs, which recruits the methylation machinery to the target DNA [3].

RNA-directed DNA methylation results in a characteristic modification pattern that is typified by methylation of cytosines in all sequence contexts (CG, CHG and CHH, where $\mathrm{H}$ is $\mathrm{A}, \mathrm{T}$ or $\mathrm{C}$ ) within the region of small RNADNA sequence homology [4]. In particular, asymmetric 
$\mathrm{CHH}$ methylation is a hallmark of RNA-directed DNA methylation. DOMAINS REARRANGED METHYLTRANFERASE2 (DRM2) is the major enzyme catalyzing de novo methylation of cytosines in all sequence contexts in response to small RNA signals [5,6]. The maintenance activities of METHYLTRANSFERASE1 (MET1) and CHROMOMETHYLASE3 act primarily to perpetuate preexisting CG and CHG methylation, respectively, during successive rounds of DNA replication [7].

Transposons, pseudogenes and non-protein coding repeats are frequent targets of RNA-directed DNA methylation $[8,9]$. By contrast, protein coding genes are generally free of RNA-directed DNA methylation unless intimately associated with repeats or transposon-related sequences [10-12]. However, up to $30 \%$ of expressed genes in Arabidopsis thaliana have in their gene bodies exclusively CG methylation that relies on MET1 and is independent of the RNA-directed DNA methylation pathway $[8,9]$. Thus, transposons and genes can be distinguished by discrete methylation patterns that are imposed by different methylation machineries. The origins of these distinct methylation patterns and their functional significance are not yet fully understood [13-15]. The biological role of CG methylation in gene bodies, which does not inhibit transcriptional elongation by Pol II, is unknown but it may prevent spurious transcription from internal promoters [16] or help to define exons [17]. An alternative proposal is that gene body methylation restrains genes from being responsive to internal or external cues, e.g. developmental or environmental signals [18].

Curiously, even though transposons are frequent targets of RNA-directed DNA methylation, only a small subset of transposons is selectively reactivated in mutants defective in this epigenetic pathway $[15,19]$. By contrast, a number of transposons are mobilized in mutants defective in MET1 or the chromatin remodeler DECREASE IN DNA METHYLATION1 $[13,20]$. Therefore, even though RNA-directed DNA methylation contributes to repression of transposons it is not the sole epigenetic modification involved in the silencing of these elements $[13,15]$.

In a search for targets of RNA-directed DNA methylation in Arabidopsis, we identified several members of a gene family encoding small cysteine-rich peptides (CRPs). These CRP genes are atypically methylated like transposons, containing CG, CHG and CHH methylation in their gene bodies. This gene body methylation, which is due in part to RNA-directed DNA methylation, is associated with gene silencing in leaves and is reduced in synergid cells of the female gametophyte where the $C R P$ genes are specifically expressed. Here we report these results and discuss the possible origin and evolutionary significance of this unusual pattern of DNA methylation.

\section{Results}

Atypical methylation pattern of CRP genes embedded in SAT5 repeats

To identify targets of RNA-directed DNA methylation in the Arabidopsis genome, we used methylation-sensitive amplification polymorphism (MSAP) [21,22]. Cutting genomic DNA with appropriate restriction enzymes that are methylation-sensitive (EcoT22I: recognition sequence ATGCAT) and methylation-insensitive (MseI: recognition sequence TTAA) allowed us to identify genomic regions that are differentially methylated at asymmetric $\mathrm{CHH}$ sites in wild-type plants compared to an nrpe1 mutant, which is impaired in the largest subunit of Pol V $[23,24]$. Two fragments identified in this analysis (Additional file 1: Figure S1) were found in a BLAST search to match unannotated intergenic regions of the Arabidopsis genome. A further sequence search against Repbase http:// www.girinst.org] revealed similarity of these fragments to the ATSAT5 repeat (referred to hereafter as SAT5), which is defined by a 2196-bp long consensus sequence [25]. SAT5 is annotated as a satellite sequence that has recently expanded near the centromere of chromosome 5 with several distantly related single copies dispersed on other chromosomes [25]. A subsequent BLAST search using the 2196-bp SAT5 repeat monomer as a query sequence identified four partial or complete single, dispersed copies of SAT5 in the Arabidopsis genome (Table 1; Additional file 2: Figure S2).

Although SAT5 was originally thought to be a nonprotein coding repeat, improvements in the annotation of the Arabidopsis genome sequence during the course of our study revealed that genes encoding small cysteine-rich peptides (CRPs) and related CRP pseudogenes are embedded in the $S A T 5$ repeat monomer (Additional file 2: Figure S2). The Arabidopsis genome contains 825 $C R P$ genes and pseudogenes that have been placed into different homology subgroups [26]. The particular subgroup associated with the $S A T 5$ repeat has been termed CRP3600, which has 57 members in Arabidopsis [26]. The CRP3600 subgroup has also been referred to as the DUF1278 family [27] and ECA1 gametogenesis-related proteins [28] http://www.arabidopsis.org. In addition to 32 copies embedded in the block of SAT5 repeat monomers close to the centromere on chromosome 5, there are an additional 25 single copies of the CRP3600 family - not all of which are embedded in a SAT5 repeat monomer-distributed on four out of the five Arabidopsis chromosomes (Figure 1; Additional file 3: Table S1). Eighteen of these are predicted to encode proteins, including a gene we have termed CRP4 (At4g09545), which is embedded in a truncated, intergenic copy of SAT5 on chromosome 4 (Table 1; Additional file 1: Figure S1). The remaining seven CRP3600 family members are likely pseudogenes, including two embedded in truncated SAT5 copies on chromosomes 2 and 5, respectively, which were identified in the MSAP analysis 
Table 1 Single dispersed copies of SAT5 repeats

\begin{tabular}{lllll}
\hline Chromosome & Sequence context & Genome coordinates & Length $(\mathbf{b p})$ & CRP gene embedded(AGI number) \\
\hline 2 & intergenic & $7845025-7844080$ & 946 & At2g18042 pseudogene \\
3 & transposon-rich & $14681750-14683927$ & 2178 & At3g42565 gene \\
4 & transposon and gene & $6038150-6037139$ & 1012 & At4g09545 gene \\
5 & intergenic & $24543172-24542491$ & 682 & At5g60978 pseudogene \\
\hline
\end{tabular}

Four single dispersed copies of the SAT5 repeat are detected in a BLAST search using the 2196 bp SAT5 consensus sequence [25] as a query sequence. One nearly full-length copy is in a transposon-rich region close to the centromere of chromosome 3 . Two truncated copies, which correspond to those detected in the MSAP analysis, are present in relatively gene-rich regions on chromosomes 2 and 5 , respectively. A third truncated copy is present in a region containing both genes and transposons on chromosome 4. The AGI numbers of the embedded CRP genes or pseudogenes are shown.

(At2g18042 and At5g60978) (Table 1; Additional file 3: Table S1).

\section{Methylation of CRP coding regions: Pol IV/Pol V-dependent $\mathrm{CHH}$ methylation}

To study methylation of the SAT5 repeat, we performed a bisulfite sequence analysis on the truncated SAT5 monomer containing the CRP4 gene (1012 bp; Table 1). This sequence contains 369 bp CRP4 coding region as well as $430 \mathrm{bp}$ upstream and $213 \mathrm{bp}$ downstream sequences (Additional file 2: Figure S2). Given its repetitive nature, we expected to detect heavy methylation throughout the SAT5 sequence. We were surprised, therefore, to find non-uniform methylation that appeared to be concentrated within the CRP4 coding region (Figure 2). One reason for this non-uniform distribution of methylation is that the number of cytosines available for methylation in CG and CHG sequence contexts
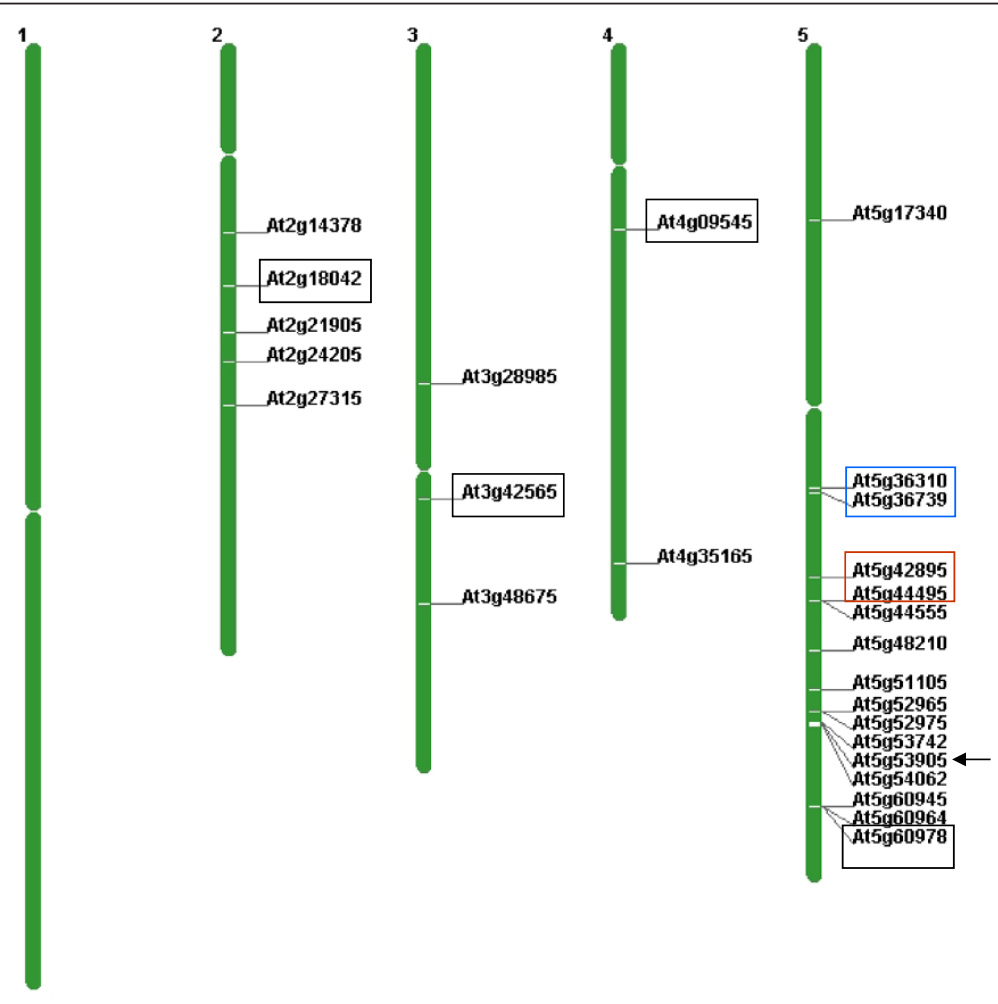

Figure 1 Chromosomal locations of CRP3600 family members. The CRP3600 subgroup has 57 members [26], 32 of which are embedded in SAT5 repeat monomers arranged in a repeat array close to the centromere of chromosome 5; the AGI numbers of only the first and last copies of the array are shown (blue box). Additional file 3: Table S1 provides the full list of the AGI numbers in between these two genes. The four single dispersed copies of the SAT5 monomer containing different CRP genes or pseudogenes on chromosomes 2, 3, 4 and 5 are boxed in black. The pseudogenes on chromosome 2 (At2g19042) and chromosome 5 (At5g60978) were identified in the original MSAP analysis. The chromosome 4 gene (CRP4: At4g09545) has been analyzed in our study, which also considers two other genes in the CRP3600 subgroup that are not embedded in a SAT5 repeat (CRP5a: At5g42895 and CRP5b: At5g44495) (boxed in red). The single member of the CRP3600 subgroup containing introns (Atg53905) is indicated by the arrow. Additional information on CRP3600 subgroup members is given in Additional file 3: Table S1. The figure was generated using the Chromosome Map Tool on the TAIR website [http://www.arabidopsis.org/jsp/ChromosomeMap/tool.jsp.]. 
differed along the length of the SAT5 repeat. The numbers were relatively low in the regions upstream (3 CGs, 6 CHGs) and downstream (2 CGs, 1 CHG) but considerably higher in the CRP4 coding region (11 CGs, 20 CHGs) (Table 2). Because at least some methylation was detected at all of the CGs and CHGs throughout the SAT5 repeat monomer (Table 2), the density of CG and CHG methylation was naturally higher within the CRP4 coding region compared to the flanking regions.

The second factor influencing the SAT5 methylation pattern was the tendency for $\mathrm{CHH}$ trinucleotides to be more frequently and more highly methylated within the CRP4 coding region than in flanking sequences. Although the number of $\mathrm{CHH}$ nucleotide groups was approximately the same in the upstream region and CRP4 coding region (51 and 52, respectively), methylation was only detected at around $22 \mathrm{CHHs}(\sim 43 \%)$ in the upstream region, which differed significantly from the 44 CHHs ( $85 \%$ ) with at least some methylation in the CRP4 coding region (Table 2). In the downstream region, methylation was detected at 19 out of $28 \mathrm{CHHs}(\sim 68 \%)$ (Table 2). In addition, the overall level of $\mathrm{CHH}$ methylation

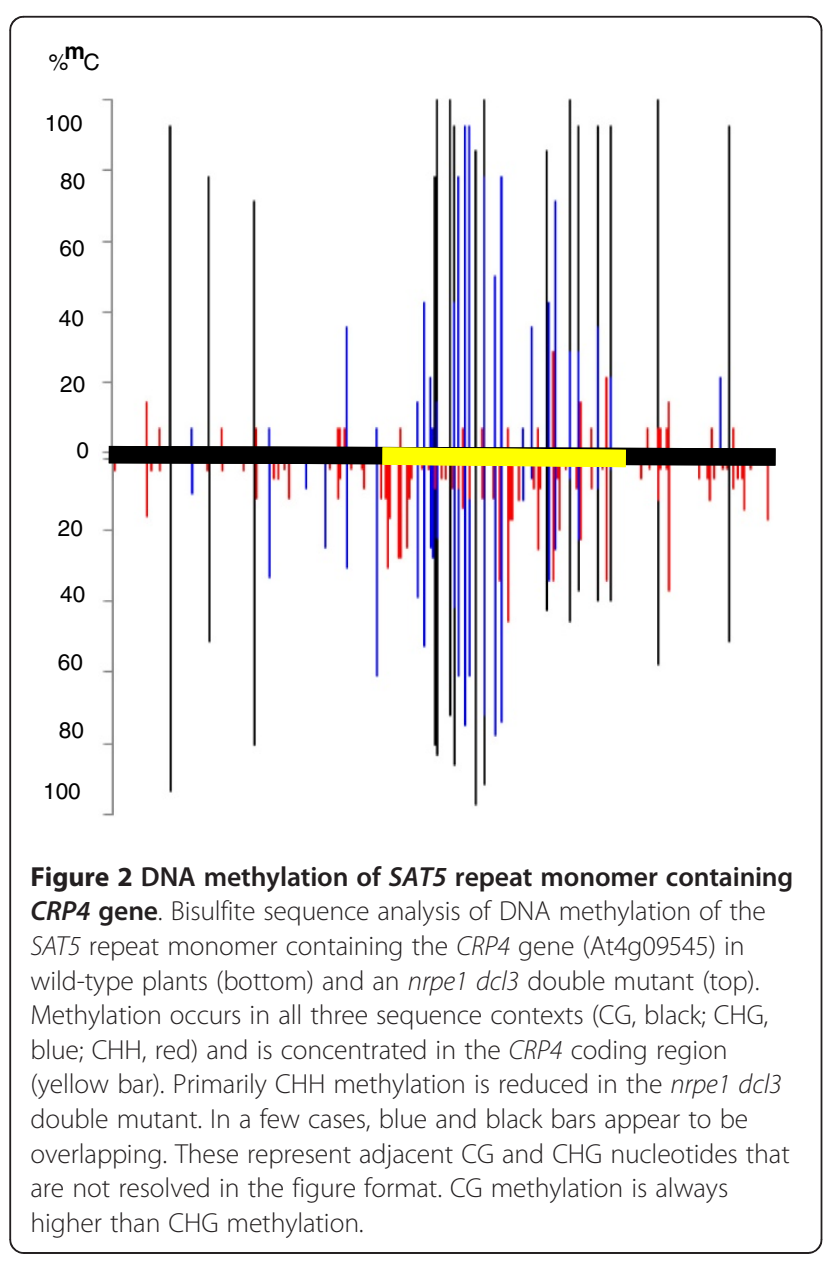

in the CRP4 coding region was $12 \%$ compared to $3 \%$ and $\sim 6 \%$ in the upstream and downstream regions, respectively (Figure $3 \mathrm{~A}$ ). Because $\mathrm{CHH}$ methylation is a hallmark of RNA-directed DNA methylation, these findings suggest that the CRP4 coding region is targeted by this epigenetic pathway. Supporting this idea, the overall level of $\mathrm{CHH}$ methylation in the CRP4 coding region was reduced $\sim 65-80 \%$ in various mutants defective in RNAdirected DNA methylation (Figure 3B). A similar pattern of dense CG, CHG and $\mathrm{CHH}$ methylation within the CRP4 coding region together with considerably less methylation in the flanking regions was observed in the whole genome bisulfite sequencing (methylome) analysis by Lister and coworkers [8], http://neomorph.salk.edu/epigenome/ epigenome.html.

The CRP4 gene is not exceptional in its methylation pattern. Several other predicted protein-coding genes in the CRP3600 family, such as At3g42565 (embedded in a SAT5 repeat; Table 1) and At5g42895 (CRP5a) and At5g44495 (CRP5b), which are not embedded in SAT5 repeats (Additional file 3: Table S1), also contain in their coding regions dense $\mathrm{CG}, \mathrm{CHG}$ and $\mathrm{CHH}$ methylation [http://neomorph.salk.edu/epigenome/epigenome.html]. This methylation is due in part to RNA-directed DNA methylation as evidenced by the loss of non-CG methylation in a $d r m 1 d r m 2 \mathrm{cmt} 3(d d c)$ triple mutant [http:// neomorph.salk.edu/epigenome/epigenome.html], which isdefective in the de novo methyltransferase DRM2 that is required for RNA-directed DNA methylation $[5,6]$.

\section{Unique Pol IV-dependent 24-nt small RNAs originating from CRP coding regions}

Our bisulfite sequencing analysis and the independent methylome analysis of Lister and coworkers [8] http:// neomorph.salk.edu/epigenome/epigenome.html suggested that methylation of the coding regions of CRP4, CRP5 $a$ and $C R P 5 b$ genes is due in part to RNA-directed DNA methylation. We therefore tested whether the requisite Pol IVdependent 24-nt small RNAs needed to induce RNA-directed DNA methylation originate from these sequences. A Northern blot analysis using a SAT5 probe readily detected 24-nt small RNAs that disappeared in Pol IV pathway mutants (nrpd1, rdr2, dcl3) (Figure 4). Because the SAT5 probe detected bulk small RNAs originating from this repeat, we used deep sequencing to investigate in more detail small RNAs arising from individual CRP genes. This analysis indeed revealed unique 24-nt small RNAs associated with the coding regions of the CRP4, CRP5 $a$ and $C R P 5 b$ genes and these small RNAs were reduced in Pol IV pathway mutants (nrpd1 and rdr2) (Figure 5).

\section{Expression of CRP genes in the female gametophyte} A previous genome-wide expression profiling analysis demonstrated that many CRP genes in the CRP3600 
Table 2 Percent methylation of individual cytosines in SAT5 repeat monomer containing the CRP4 gene

\begin{tabular}{lllllll}
\hline Col-0 & methylated CG & unmethylated CG & methylated CHG & unmethylated CHG & methylated CHH & unmethylated CHH \\
\hline upstream & $3 / 3(100 \%)$ & $0 / 3$ & $6 / 6(100 \%)$ & $0 / 6$ & $22 / 51(\mathbf{4 3} \%)$ & $29 / 51(57 \%)$ \\
CRP4 cds & $11 / 11(100 \%)$ & $0 / 11$ & $20 / 20(100 \%)$ & $0 / 20$ & $44 / 52(\mathbf{8 5} \%)$ & $8 / 52(15 \%)$ \\
downstream & $2 / 2(100 \%)$ & $0 / 2$ & $0 / 1$ & $1 / 1(100 \%)$ & $19 / 28(\mathbf{6 8} \%)$ & $9 / 28(32 \%)$ \\
\hline
\end{tabular}

The total number of cytosines and those that are methylated or unmethylated in each sequence context $(\mathrm{CH}, \mathrm{CHG}, \mathrm{CHH})$ are shown for each region of the SAT5 repeat monomer containing the CRP4 gene [upstream, CRP4 coding sequence (cds), downstream]. The percentage of methylated or unmethylated cytosines is shown in parentheses except where the value is $0 \%$. Percentages for methylated cytosines in a CHH context (indicative of RNA-directed DNA methylation) are shown in red. The difference for the upstream region vs. CRP4 cds is significant ( $p=0.000013$; two-tailed Fisher's exact test [http://www.graphpad.com/quickcalcs/ index.cfm]). For the downstream region, the difference is not significant ( $p=0.093)$ but this may reflect the lower number of cytosines in the downstream region.

subgroup, including CRP5 a and CRP5b, are expressed in the egg apparatus (egg and synergid cells) of the female gametophyte [27]. However, the expression patterns of the four CRP3600 subgroup members embedded in single copy SAT5 repeat monomers (two genes and two pseudogenes) (Table 1) has not yet been reported. Using semi-quantitative RT-PCR, we detected transcripts from these two genes and two pseudogenes in flowers but not leaves, and with the exception of the pseudogene At2g18042, transcription is not strongly reactivated in mutants defective in RNA-directed DNA methylation (Figure 6A).

To obtain a more detailed view of the cell type-specific expression pattern, we generated constructs encoding a GUS reporter protein and a CRP4-GFP fusion protein, both under the control of a CRP4 promoter fragment, which comprises 921 bp upstream of the ATG start codon of the CRP4 gene. After introducing these constructs into wild-type Arabidopsis plants, GUS and CRP4-GFP gene expression was observed specifically in the synergid cell region of the female gametophyte, indicating that the CRP4 promoter is active exclusively in these cells (Figure 6B). We therefore infer that the detection of CRP4 transcripts in flowers of non-transgenic plants (Figure 6A) reflects expression of the endogenous CRP4 gene in synergid cells.

\section{CRP4 coding sequence is not methylated when} transcribed by Pol II to produce a translatable mRNA

To study methylation of the CRP4 coding region in cells where the CRP4 promoter is active, we isolated DNA from synergid cells of a transgenic plant expressing a CRP4-GFP fusion gene under the control of the CRP4 promoter. A PCR-based approach was used to examine methylation in the CRP4 coding sequence of this fusion gene as well as the endogenous CRP4 gene. For this, DNA was digested with either HpaII (reporting on CG methylation) or DdeI (reporting on $\mathrm{CHH}$ methylation), and PCR amplification was performed using primers specific for the CRP4 coding sequence in either the endogenous CRP4 gene or the CRP4-GFP fusion gene. In both cases, little or no amplification product was observed when using synergid cell DNA, indicating reduced methylation of the endogenous and transgenic CRP4 coding sequences in cells where the CRP4 promoter is active (Figure 7). By contrast, a strong amplification product indicating the presence of DNA methylation was seen for both the endogenous and transgenic CRP4 sequences when using leaf DNA (Figure 7). The latter results are consistent with the bisulfite sequence analysis on leaf DNA, which revealed dense methylation in the CRP4 coding region of both
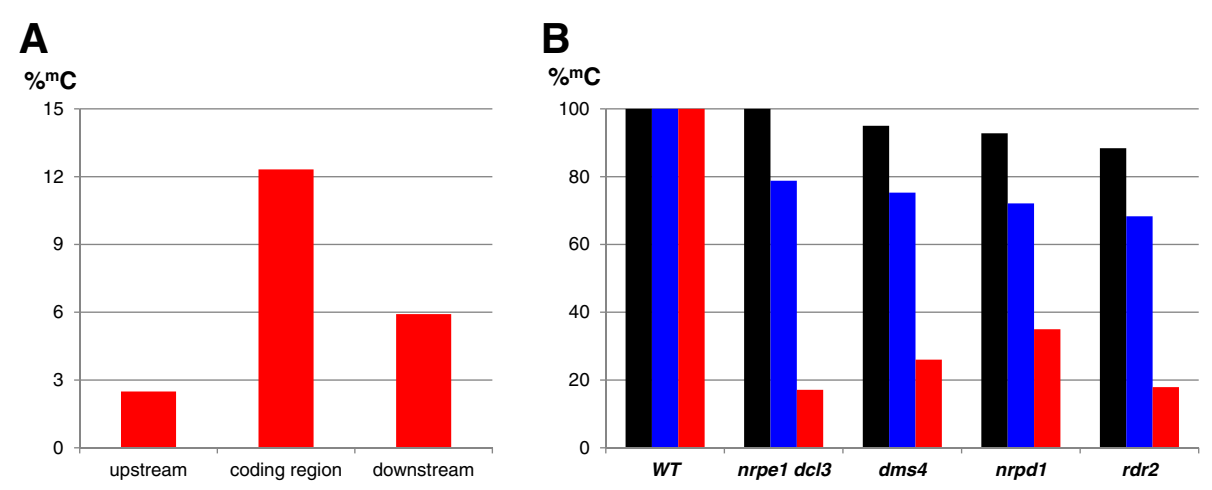

Figure 3 CHH methylation in CRP4 coding region. A) Average percent methylation of cytosines in a CHH context in different parts of the SAT5 repeat monomer containing the CRP4 gene. CHH methylation is highest in the CRP4 coding region. B) Overall levels of methylation in CG (Black), CHG (blue) and $\mathrm{CHH}$ (red) nucleotide groups in the CRP4 coding region in wild type plants (WT) and mutants defective in RNA-directed DNA methylation (nrpe1 dcl3 double mutant and dms4, nrpd1, and rdr2 single mutants). Primarily $\mathrm{CHH}$ methylation is lost in the mutants. 


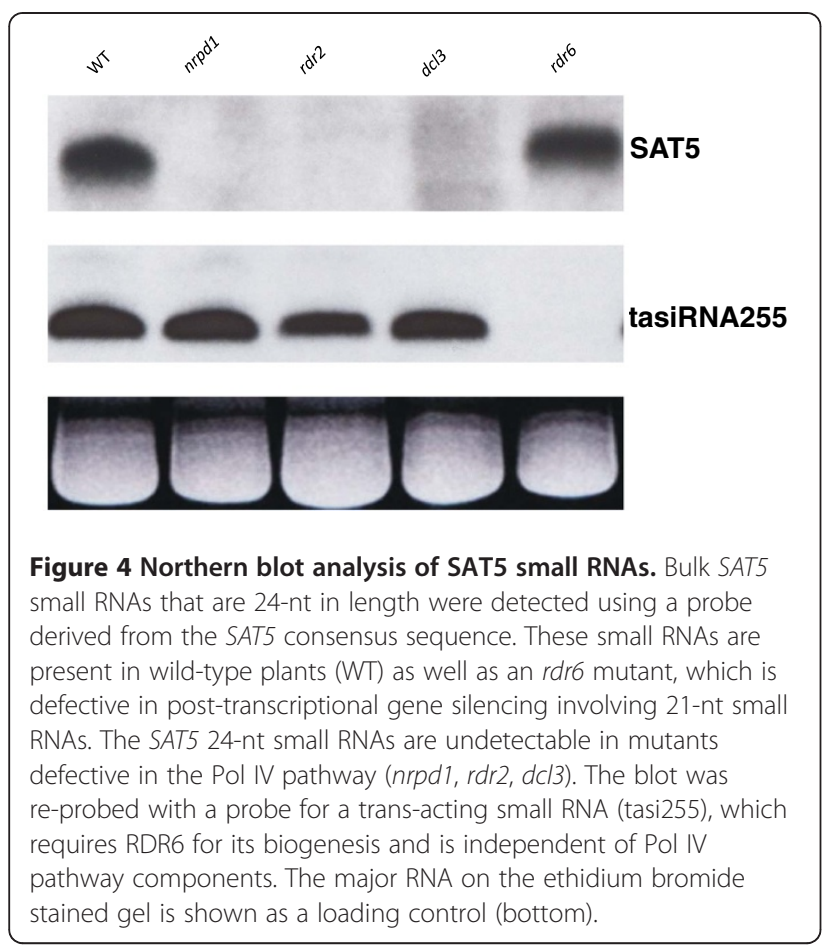

the endogenous CRP4 gene (Figure 2) and the CRP4 promoter-driven CRP4-GFP fusion (Figure 8A, right).

We obtained further evidence that the CRP4 coding sequence is unmethylated when transcribed by Pol II by examining methylation of a CRP4-GFP fusion gene under the control of the constitutive $35 \mathrm{~S}$ promoter in leaves. In transgenic plants containing this construct, the CRP4 coding sequence of the CRP4-GFP fusion gene remained largely unmethylated (Figure 8A, left). Moreover, a CRP4-GFP fusion protein was detectable on Western blots in these plants, indicating Pol II transcription of a translatable CRP4-GFP mRNA from the $35 \mathrm{~S}$ promoter (Figure $8 \mathrm{~B}$, lanes $1-4$ ). By contrast, the CRP4 coding sequence of a CRP4-GFP fusion gene under the control of the CRP4 promoter acquired methylation similar to the endogenous CRP4 gene (Figure $8 \mathrm{~A}$, right) and no CRP4-GFP fusion protein was detected in plants containing this construct (Figure 8B, lanes 5,6). Thus, CRP4 coding sequences transcribed by Pol II lack methylation in both synergid cells, where the endogenous CRP4 gene and CRP4-GFP fusion gene are expressed from the CRP4 promoter, and in leaves, where the fusion gene is under the control of the constitutive $35 \mathrm{~S}$ promoter.

The CRP4 gene is not inducible by flg22 or heat treatment in seedlings

The endogenous CRP4 gene was not de-repressed in the leaves of mutants defective in RNA-directed DNA methylation (Figure 6A) but it is possible that biotic or abiotic stresses might reactivate the CRP4 gene. Given the suggested roles of CRPs in microbial defense [29], we tested whether the CRP4 gene was induced after treatment of seedlings with the bacterial flagellin peptide flg22, which is a potent elicitor of the innate immune response in plants [30]. Although we observed induction of MPK3 (At3g45640), a known flagellin-induced gene [31], no induction of the CRP4 gene was observed under the same conditions (Figure 9A). Similarly, we did not observe induction of the CRP4 gene after heat stress that was sufficient to activate the Onsen retrotransposon (Figure 9B), which requires Pol IV pathway components to restrict trans-generational transposition [19].

\section{Discussion}

Current views of DNA methylation patterns in plants hold that gene body methylation occurs primarily in a CG context and that non-CG methylation is limited to transposons and non-protein-coding repeats [13,32]. Contrary to this view, we have identified several genes encoding CRPs in Arabidopsis that atypically contain in their gene bodies not only CG but also CHG and $\mathrm{CHH}$ methylation, which arises in part from RNA-directed DNA methylation. These genes are thus methylated like transposons in their coding regions. Evidence for this claim includes the detection of Pol IVdependent 24-nt small RNAs that are unique to each gene and the reliance of full $\mathrm{CHH}$ methylation on components of the Pol $\mathrm{V}$ pathway. In addition to RNA-directed DNA methylation, other methylation pathways contribute to the dense methylation of $C R P$ gene bodies in leaves. This is indicated by the persistence of nearly wild-type levels of CG and CHG methylation in mutants defective in RNA-directed DNA methylation, which lose predominantly $\mathrm{CHH}$ methylation. Multiple layers of epigenetic modifications have been observed previously for other targets of RNA-directed DNA methylation in plants $[13,15,32,33]$. The biological role of the transposon-like methylation pattern of CRP gene bodies is not yet clear but it is likely to be related to gene silencing in the sporophyte. As discussed below, alternative functions can also be considered.

The CRP genes investigated in this study are silent and methylated in leaves and, given the restricted expression pattern of the CRP4 promoter when fused to GUS and GFP reporter genes, presumably in other sporophytic tissues as well. As shown here and elsewhere [27], the promoters of many CRP genes in the CRP3600 family are active specifically in the egg apparatus region of the female gametophyte (i.e. egg and synergid cells). The functions of CRPs in the female gametophyte are not yet clear but possibilities include acting as pollen tube attractants [34], antimicrobial substances in the vulnerable egg cell region $[29,35,36]$, or intercellular signaling molecules during female gametophyte development [37-39]. In our experiments, the synergid cellspecific expression of the CRP4-GFP fusion gene, and presumably the CRP4 endogenous gene, was correlated with a loss of $\mathrm{CG}$ and $\mathrm{CHH}$ methylation in the CRP4 gene body 
at the restriction sites tested. This finding suggests a connection between the observed gene body methylation and CRP4 gene silencing in leaves. We assume a similar association holds true for the CRP5 $a$ and $C R P 5 b$ genes, which are highly methylated in their gene bodies in leaf tissue [http://neomorph.salk.edu/epigenome/epigenome.html] yet expressed exclusively in the egg apparatus region of the female gametophyte [27].

The influence of gene body methylation on expression depends on the sequence context of methylated cytosines. In wild-type plants, CG methylation alone in gene bodies does not inhibit transcriptional elongation and is found at many moderately expressed genes
$[8,9,13,16]$. CHG methylation in gene bodies, which is induced in the ibm1 (increase in BONSAI methylation1) mutant, has variable effects on transcription, with only some target genes showing decreased transcription while others are unchanged or even more highly expressed [40]. By contrast, our results suggest that a combination of dense CG and non-CG methylation in gene bodies is associated with gene silencing. Whether this methylation inhibits transcriptional elongation by Pol II or is the default state when transcription is impaired by other means is not yet known. Also unclear is how methylation in CRP4 gene bodies is lost in synergid cells. It may result from active demethylation by DNA glycosylase

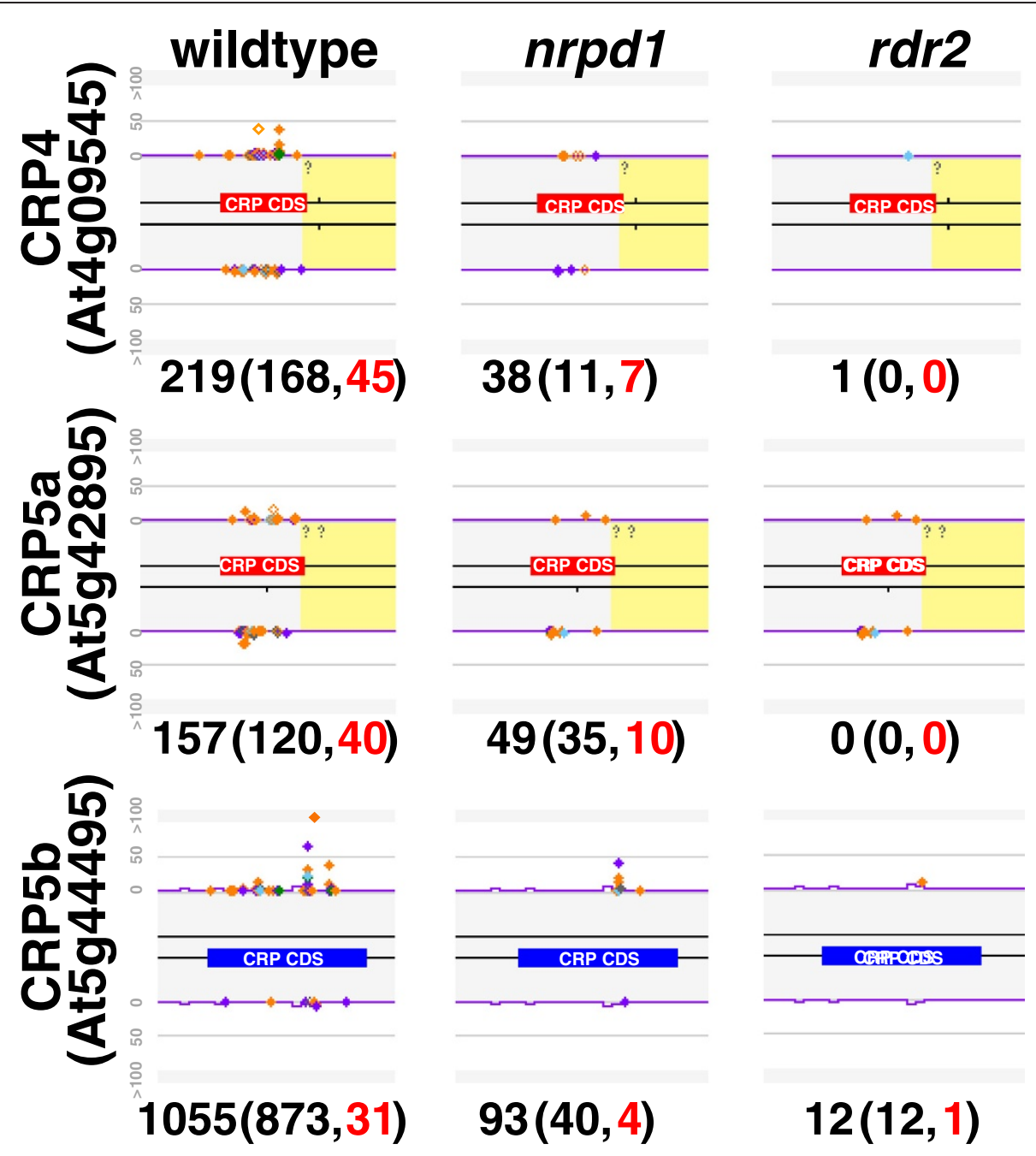

Figure 5 Small RNAs originating from specific CRP coding regions. Individual abundances for small RNA signatures between 21-24 nt in length are displayed in different colors (24-mers are orange). A unique small RNA signature is displayed as a filled diamond and a duplicated small RNA signature is displayed as a hollow diamond. The exons of CRP4, CRP5a and CRP5b genes are annotated as blue or red boxes. Purple lines indicate a k-mer frequency for repeats; yellow shading indicates DNA transposon-like sequences found by RepeatMasker. Note that the majority of small RNAs originate within the CRP coding regions and not in the adjacent transposon-like sequences. The small RNA abundances were normalized to 5 transcripts per million (TPM). The sum of hits-normalized-abundance (HNA) for all small RNAs mapping to the entire gene is displayed below each gene image with the total abundance of $24 \mathrm{nt}$ siRNAs in parentheses in black, followed by the count of unique $24 \mathrm{nt}$ siRNAs in red text. 


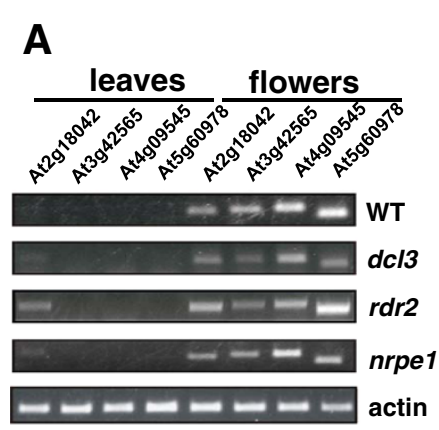

B

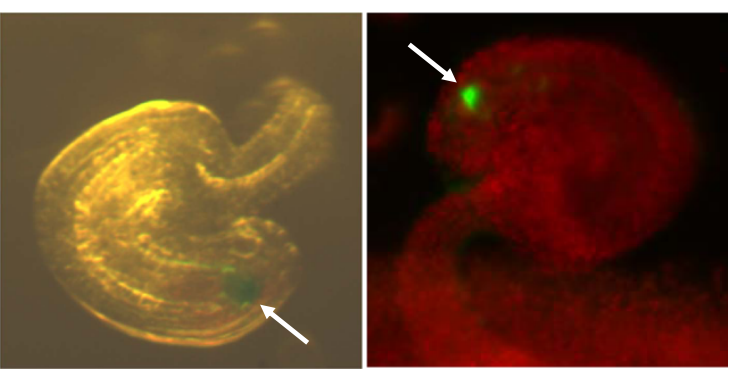

Figure 6 Flower and synergid cell-specific expression of CRP genes and the CRP4 promoter. (A) Semi-quantitative RT-PCR demonstrates expression of endogenous CRP genes (At3g49565, At4g09545) and CRP pseudogenes (At2g18042, At5g60978) in flowers but not in leaves. With the exception of the pseudogene At2g18042, which shows some reactivation in leaves in mutants defective in RNA-directed DNA methylation (dcl3, At3g43920; rdr2, At4g11130; nrpe1, At2g40030), none of the genes or pseudogenes are appreciably expressed in these mutants. Actin (At3g18780) is shown as a constitutively expressed control. (B) Photographs of ovules from transgenic Arabidopsis plants transformed with constructs containing CRP4-GFP (right) and GUS (left) reporter genes under the control of the CRP4 promoter. Expression occurs exclusively in the synergid cell region of the female gametophyte (arrows). Identical results were obtained in multiple independent transgenic lines obtained for each construct.

activities, as observed for imprinted genes in the central cell of the female gametophyte [41,42], or a lack of silencing factors in synergid cells or their precursors. A recent global enrichment study demonstrated that genes encoding components of the RNA-directed DNA methylation machinery, in particular six PAZ-domain proteins, are predominantly expressed in egg cells but some are also expressed in synergid cells [43]. Loss of CRP4 gene body methylation in synergid cells may also reflect the restricted cellular distribution of essential transcription factors, such as the synergid cell-specific transcription factor MYB98 $[27,44]$. However, there does not seem to be a correlation between methylation of CRP genes in leaves and a requirement for MYB98 in synergid cell-

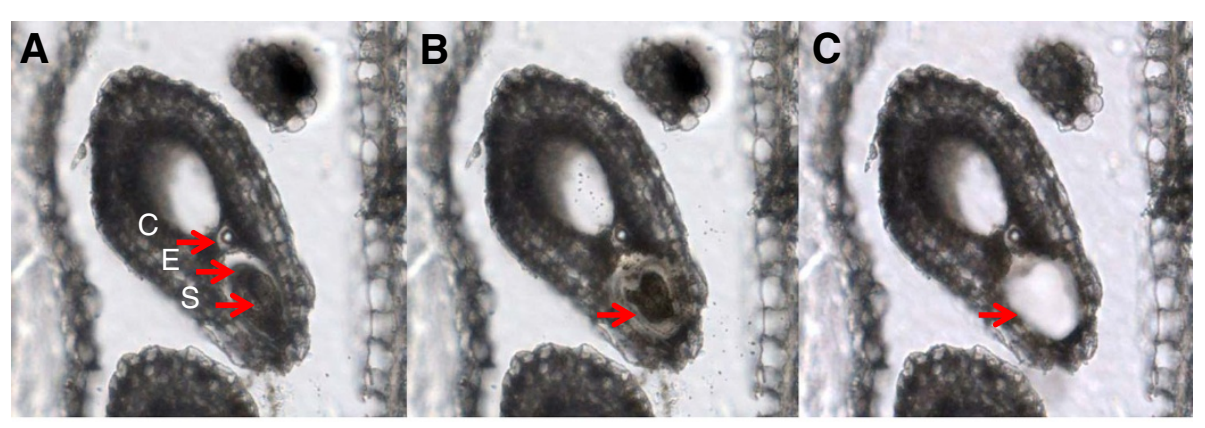

D

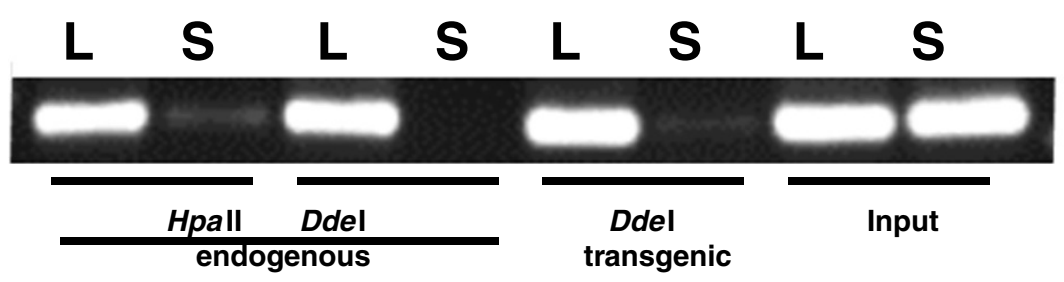

Figure 7 Laser-Assisted Microdissection and subsequent DNA methylation analysis of CPR4 sequences in synergid cells from mature embryo sacs. (A) Dissection of the synergid cell from a mature embryo sac; an $8 \mu \mathrm{m}$ section through an ovule bearing a mature embryo sac prior to laser microdissection with the MMI CellCut Plus instrument. The following abbreviations are used: S, synergids; E, egg cell; C, central cell. (B) The ultraviolet laser beam has been applied in order to isolate the synergid cells (arrow). The laser cut has a diameter of 1-2 $\mu$ m. (B) The synergid cell has been removed with an MMI isolation cap. (D) DNA methylation analysis. Cytosine methylation of the CRP4 coding sequence was studied in synergid cell $(\mathrm{S})$ and leaf genomic DNA $(\mathrm{L})$, in both endogenous and transgenic contexts, using enzymes sensitive to $\mathrm{CG} / \mathrm{CHG}$ methylation (Hpall) and CHH methylation (Ddel). The CRP4 coding region has two sites for Hpall and three sites for Ddel. Disappearance or reduced levels of a fragment after digestion with a given enzyme indicate loss of methylation at that site. Undigested input DNA is included at the far right. 
A

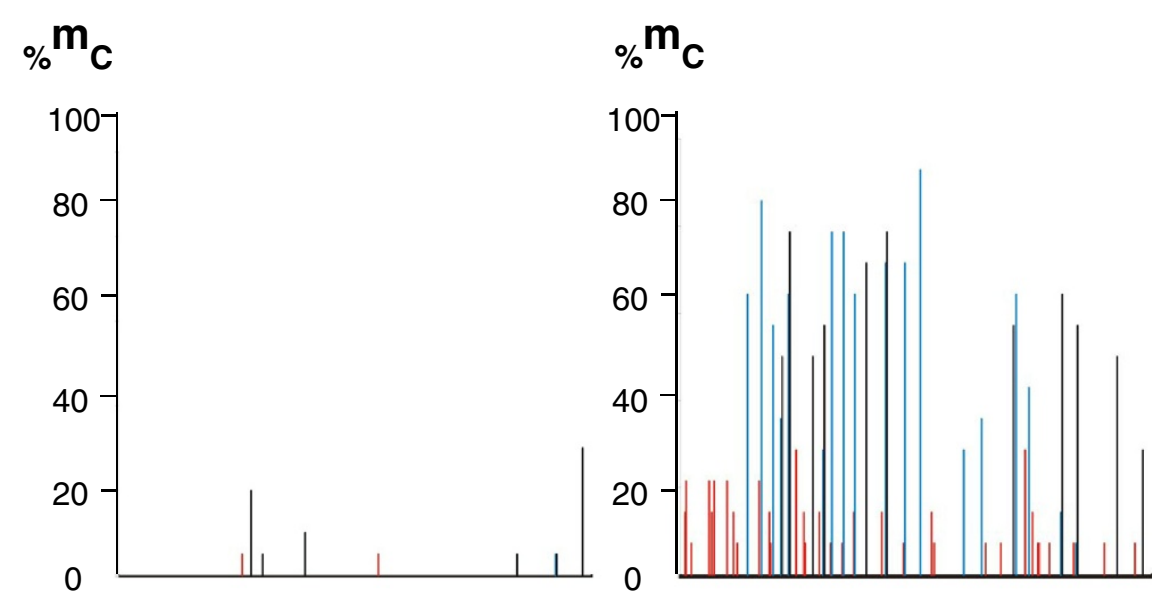

B
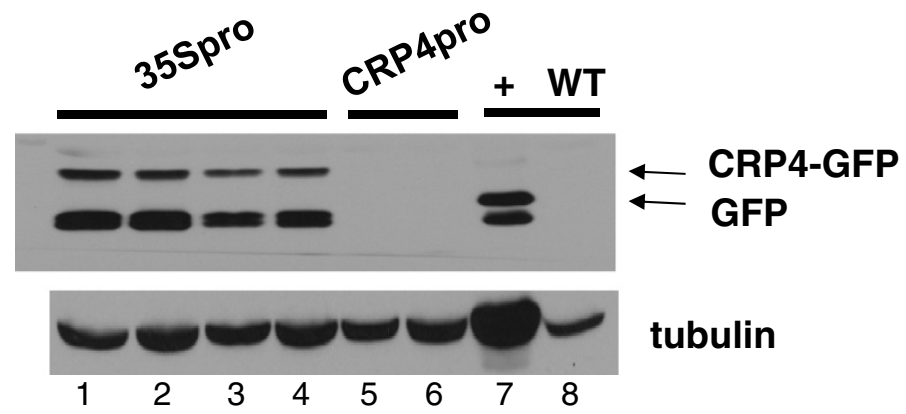

Figure 8 CRP4 coding sequence is unmethylated in leaves when transcribed from 35S promoter to produce translatable mRNA. (A) Bisulfite sequencing to assess methylation in leaves of the CRP4 coding region in a CRP4-GFP fusion gene under the control of the constitutive 355 promoter (left) and the synergid cell-specific CRP4 promoter (right). The region shown corresponds to that indicated by the yellow bar in Figure 2. We also performed bisulfite sequencing on the GFP coding sequence in the CRP4 promoter-directed construct but observed no methylation (data not shown). (B) Western blot detection of the CRP-GFP fusion protein in seedlings from four independent transgenic lines transformed with a 35 S promoter-CRP4-GFP fusion construct (lanes 1-4, top band, top arrow). The ' + ' lane shows control GFP expression in a previously published transgenic line (top band, bottom arrow) $[23,24]$. The lower band in these lanes probably corresponds to a degradation product that reacts with the GFP antibody. A CRP4-GFP fusion protein is not detected in transgenic plants containing a CRP4-GFP fusion gene under the control of the CRP4 promoter (lanes 5 and 6; results from two independent lines shown). Tubulin is shown as a constitutively expressed control.

specific expression. For example, both CRP5a and CRP5b are methylated in leaves and expressed in synergid cells but only the former requires MYB98 [27].

Although gene silencing seems the most likely function and/or consequence of combined CG and non-CG methylation in the CRP gene bodies, a possible positive role can also be considered, namely that gene body methylation attunes genes to internal or external cues. This suggestion follows from recent data demonstrating that gene body methylation, whether in a CG or non-CG context, can be dynamic and may render genes sensitive to developmental or environmental signals. For example, a bioinformatics study examining genome-wide gene expression in Arabidopsis under many different experimental conditions concluded that CG methylation in gene bodies protects genes from reacting to internal or external stimuli [18]. In tomato, a drought-responsive gene that atypically has non-CG methylation in the gene body loses non-CG methylation and gains CG methylation under drought conditions [45]. Some transcribed genes in human embryonic stem cells contain in their gene bodies non-CG methylation that is lost as cells differentiate and re-established during de-differentiation, suggesting a relationship between non-CG methylation in gene bodies and the differentiation state of the cells $[14,46]$. In view of these findings, it is conceivable that combined CG and non-CG methylation in CRP gene bodies allows responsiveness to either developmental cues in the female gametophyte or external factors in the environment. Regarding the latter possibility, we did not observe de-repression of the methylated CRP4 gene in leaf tissue following treatment with flg22 or heat stress, but other biotic or abiotic stresses can be tested in the future. 
A

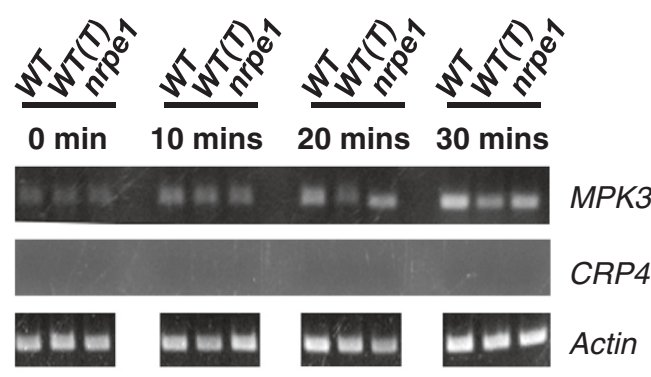

B

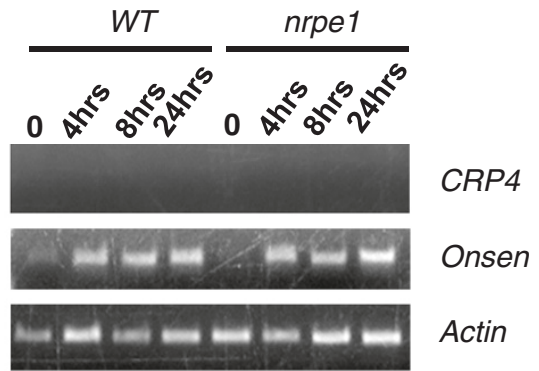

Figure 9 The CRP4 gene is not induced in seedlings following flg22 treatment or heat stress. Semi-quantitative RT-PCR was used to test possible induction of CRP4 gene expression in seedlings under different conditions. (A) Treatment of seedlings with the bacterial elicitor flg22 for the indicated time periods results in induction of expression of the MAP kinase MPRK3 [31] but not the CRP4 gene. Similar results were seen in wild-type non-transgenic seedlings (WT), a wild-type transgenic line [WT(T)], and an nrpel mutant, which is defective in the largest subunit of Pol V. (B) Heat treatment of seedlings for the indicated time periods does not result in induction of CRP4 gene expression whereas the Onsen retrotransposon is induced under the same conditions [19]. In both panels, actin expression is shown as a constitutively expressed control.

Why are the gene bodies of some CRP3600 gene family members methylated like transposons? Although several methylated CRP genes are embedded in SAT5 repeats this is not the case for all (for example, CRP5a and $C R P 5 b$ ), demonstrating that the presence of the flanking SAT5 sequences is not a requirement for methylation. To explain the dense methylation concentrated in the $C R P$ coding regions, we propose that some members of the CRP3600 gene family arose through reverse transcription of mature mRNAs (retroposition) and hence can be classified as retroposed genes (retrogenes). Under this hypothesis, an intron-containing progenitor copy would have been highly expressed in the egg cell or one of its precursors in the germline, the spliced mRNA reverse transcribed, and the cDNA subsequently integrated into egg cell DNA to become a heritable part of the genome. Through this copying and integration process, CRP retrogenes would resemble transposons and be methylated accordingly in their coding regions. Consistent with this hypothesis, only one gene in the CRP3600 family has two introns (At5g53905) while the rest are intron-free and thus candidate retrogenes (Table 2). The observation that at least some CRP3600 gene family members are probably expressed in the egg cell as well as the neighboring synergid cells [27] is compatible with the retrogene hypothesis. Interestingly, retrogenes in mammals are expressed mainly in the testes, where transcription is less tightly regulated than in somatic tissues [47]. Whether controls on transcription are similarly relaxed in synergid cells and/or egg cells in plants remains to be determined.

Not all copies of the CRP3600 gene family have a transposon-like methylation pattern in their gene bodies. Some lack methylation entirely and one has CG methylation only (Additional file 3: Table S1). Although the source of such differences is presently unknown, one possibility is that recently integrated copies still have the initial transposon-like methylation pattern, which over time degenerates into exclusively CG methylation, ultimately resulting in the complete decay of gene body methylation. Because methylated cytosine spontaneously deaminates to produce thymine, methylated CRP coding regions may experience accelerated sequence diversification over evolutionary time, thus promoting functional diversification of CRP proteins. Given known or proposed roles of CRPs in pollen tube guidance [34] and self-incompatibility $[38,48]$, such sequence changes and functional diversification may help to drive speciation.

\section{Conclusions}

We have identified several genes of the Arabidopsis CRP3600 subgroup that have an unusual transposon-like methylation pattern consisting of $\mathrm{CG}, \mathrm{CHG}$ and $\mathrm{CHH}$ methylation in their gene bodies. This methylation, which was observed in leaves, appears to be associated with gene silencing in sporophytic tissues because it decreases in synergid cells of the female gametophyte, where the CRP genes are specifically expressed. Analysis of CRP3600 gene family members suggests that at least some methylated copies may have arisen through retroposition, causing them to be epigenetically modified like transposons through RNA-directed DNA methylation and other methylation pathways that target mobile elements. The CRP genes will be useful models for studying developmentally-regulated changes of combined CG and non-CG methylation in gene bodies and the expansion through retrotransposition of gene families expressed in the plant germline.

\section{Methods}

Plants

All experiments have been performed using Arabidopsis thaliana accession Col-0. For the mutants defective in RNA-directed DNA methylation the alleles used were 
drd3-7 (for nrpe1) [23], rdr2-1 (SAIL_1277H08; [49], nrpd1-7 (formerly nrpd1a-7; [50]), dms4-1 [51], dcl3-1 (SALK_005512; [49]) and rdr6-1 [52]. Mutants were genotyped using primers shown in Additional file 4: Table S3. Plants were cultivated on potting soil in either a greenhouse or growth chamber set at $\sim 21^{\circ} \mathrm{C}$ with a 16 hour light/8 hour dark cycle.

\section{Constructs and plant transformation}

For expression studies, three constructs were made: 35Spromoter-CRP4-EGFP, CRP4promoter-CRP4-EGFP, and CRP4promoter-GUS. To assemble the constructs, the CRP4 promoter region (consisting of $921 \mathrm{bp}$ upstream of ATG start codon) and the CRP4 coding region (369 bp) were modified with restriction enzyme sites that are necessary for the plasmid construction [modified sequence synthesized by Mr.Gene (Regensburg, Germany)]. For construction of the CRP4-GFP fusion gene, a sequence encoding enhanced green fluorescent protein (EGFP, referred to hereafter as GFP) was added to the C-terminus of CRP4 (including both promoter and coding region). We also fused the same GFP coding sequence to the $\mathrm{C}$-terminus of the CRP4 coding region, which was driven by the cauliflower mosaic virus $35 \mathrm{~S}$ promoter. Both of these fragments were inserted into a pPZP221 binary vector [53], which has a gentamicin selection marker driven by the $35 \mathrm{~S}$ promoter [54] for selection of transformed plants. To construct the $B$-glucuronidase (GUS) reporter under the control of CRP4 promoter, a GUS coding sequence (plasmid pRT102) [55] was inserted downstream of the CRP4 promoter and introduced into pPZP221 binary vector [53].

All three plasmids (pPZP 35Spromoter-CRP4-GFP, pPZP CRP4 promoter-CRP4-GFP, and pPZP CRP4promoterGUS ) were transferred into Agrobacterium tumefaciens strain ASE using triple mating [56] and transgenic plants were obtained by using the floral dip method [57].

Methylation-sensitive amplification polymorphism (MSAP) MSAP analysis was performed according to a published procedure [21] with some modifications. Genomic DNA was isolated using the Qiagen DNAeasy Maxi Kit (Qiagen, Hilden, Germany) and $1 \mu \mathrm{g}$ of genomic DNA was digested with EcoT22I/MseI overnight. Fifty pMol MseI adapters and 5 pMol PstI adapters were added and ligation was performed for $3 \mathrm{hrs}$ at $37^{\circ} \mathrm{C}$. Sterile $\mathrm{H} 2 \mathrm{O}$ up to $500 \mu \mathrm{l}$ was added and the samples were stored at $-20^{\circ} \mathrm{C}$ until use. Adapters were prepared by adding equimolar amounts of both strands.

For PCR reactions, the EcoT22I primer was radioactively labeled using $\left[\gamma^{32} \mathrm{P}\right]$ ATP and T4 polynucleotide kinase (reaction carried out on ice) (Roche, Vienna, Austria). The following PCR program was used: 1 cycle: 1 minute $94^{\circ} \mathrm{C}$, 30 seconds $65^{\circ} \mathrm{C}, 1$ minute $72^{\circ} \mathrm{C}$ afterwards the annealing temperature was lowered each cycle by $0.7^{\circ} \mathrm{C}$ during 12 cycles. This gave a touch down phase of 13 cycles. This was followed by: 23 cycles: 30 seconds $94^{\circ} \mathrm{C}, 30$ seconds $56^{\circ} \mathrm{C}, 1$ minute $72^{\circ} \mathrm{C}$; 10 minutes $72^{\circ} \mathrm{C} ; \infty 4^{\circ} \mathrm{C}$. PCR products were electrophoresed on $5 \%$ polyacrylamide7.5 M urea-gels [acrylamide:bis-acrylamide, 19:1, (Roth, Karlsruhe, Germany]. Pre-electrophoresis was run at 60 Watt for 30 minutes in $1 \mathrm{x}$ TBE running buffer until plates were at approximately $45^{\circ} \mathrm{C}$. Electrophoresis was performed for 2 hours 30 minutes at 60 Watt until xylene cyanol was two-thirds down of the length of the gel. Gels were blotted onto 3MM Whatman filter paper covered with Saran Wrap and dried in the gel dryer for 2 hours 30 minutes at $80^{\circ} \mathrm{C}$. The gels were exposed to Kodak BioMax MS Film overnight at room temperature.

Bands showing polymorphisms were cut out from the $3 \mathrm{MM}$ Whatman filter paper. $100 \mu \mathrm{l}$ sterile $\mathrm{H}_{2} \mathrm{O}$ was added and the bands were incubated $\mathrm{o} / \mathrm{n}$ at $4^{\circ} \mathrm{C}$. DNAs were reamplified and cloned into the pGEM-T Easy vector (Promega, Vienna, Austia). The following PCR program was used for re-amplification: $95^{\circ} \mathrm{C} 2$ minutes; $95^{\circ} \mathrm{C} 10$ seconds, $56^{\circ} \mathrm{C} 20$ seconds, $72^{\circ} \mathrm{C} 1$ minute 30 seconds, 35 cycles; $72^{\circ} \mathrm{C} 7$ minutes. Cloned fragments were re-run on an MSAP gel side by side with the genomic DNA fragments to make sure that the correct fragment was cloned and to check the reproducibility of the polymorphism. Robust polymorphic bands were sequenced.

Primers used to detect and clone the chromosome 2 SAT5 copy were T21 (5'-GAC TGC GTA GGT GCA TCC-3') and M56 (5'-GAT GAG TCC TGA GTAATG T-3'). For the chromosome 5 SAT5 copy, the primers used were T21 (see above) and M1 (5'GAT GAG TCC TGA GTA ATA-3').

\section{Bisulfite sequencing}

Genomic DNA was isolated from rosette leaves using a DNeasy Plant Maxi kit (Qiagen, Hilden, Germany). Bisulfite treatment of DNA was conducted using a EpiTect Bisulphite kit (Qiagen, Hilden, Germany) according to the manufacturer's instructions with several modifications as described previously [58]. The PCR reactions were performed using Advantage 2 Polymerase Mix from Clontech (Mountain View, California) and the conditions for the amplification of bisulfite-treated DNA were as follows: $94^{\circ} \mathrm{C}$ for $2 \mathrm{~min}$ followed by 34-39 cycles at $94^{\circ} \mathrm{C}$ for $30 \mathrm{sec}, 30 \mathrm{sec}$ annealing temperature for a particular primer pair (see Additional file 4: Table S3), $68^{\circ} \mathrm{C}$ for $45 \mathrm{sec}$, and $6 \mathrm{~min}$ of final elongation. The PCR was carried out in a total reaction volume of $50 \mu \mathrm{l}$. As a control for complete bisulfite conversion, we used the PHAVOLUTA gene [59]: PCR conditions are the same as above except for the first pair of primers we used 40 cycles and for the second pair 35 cycles. Primers are shown in Additional file 4: Table S3. The 1012 bp SAT5 copy containing the CRP4 gene was analyzed in three 
overlapping parts. The results shown in Figure 2 are from sequencing of at least 15 clones of each part in wild-type and mutant plants.

\section{Small RNA isolation and Northern blot analysis}

Small RNAs were isolated from pooled 21-day-old Arabidopsis seedlings or inflorescence tissues using the mirVana miRNA isolation kit (Ambion/Applied Biosystems, Brunn am Gebirge, Austria) and analysed by Northern blot hybridization according to a published procedure $[23,33,58]$. We used an end-labeled oligonucleotide probe to detect tasiRNA255 (5'-TAC GCT ATG TTG GAC TTA GAA-3') and an end-labeled LNA (locked nucleic acid) oligonucleotide (5'-AAL CAA LAA TLG TTL GGT LCA TLC CGL TGA LTG GLA TAL TTC LCT GLG ATL GCA-3' as a probe to detect bulk SAT5 small RNAs.

\section{Small RNA sequencing}

Libraries of small RNAs were constructed from total RNA isolated from mixed stage inflorescence tissues of wild type (wt) Arabidopsis Col-0, mutants nrpd1 and $r d r 2$ using TRIzol reagent (Invitrogen). Total RNA $(200 \mu \mathrm{g})$ for each sample was used to construct the small RNA librarires as described previously but with different adapters. The RNA oligos (Dharmacon) used for small RNA ligations were as follows: 5' RNA Adapter $\left(5^{\prime} \mathrm{OH}-\right.$ GUUCAGAGUUCUACAGUCCGACGAUC-OH $3{ }^{\prime}$ ) and 3' RNA Adapter: (5' pUCGUAUGCCGUCUUCUGCUUGUidt 3'; p, phosphate; idT, inverted deoxythymidine). Libraries were sequenced on an Illumina HiSeq2000 at the Delaware Biotechnology Institute. This generated $12,043,425$ total reads from wt Col-0, 13,580,575 from mutant $n r p d 1$ and 9,001,733 from mutant $r d r 2$.

Adapter sequences were removed using a Perl script, generating small RNA sequences plus abundances. The data were matched to the Arabidopsis genome (TAIR v9). Of the $12,043,425$ total reads from wt Col-0, $13,580,575$ from mutant $n r p d 1$ and 9,001,733 from mutant $r d r 2$, 8,577,577 (wt), 2,858,557 (nrpd1) and $4,322,052$ ( $r d r 2$ ) reads matched the genome, excluding 1,709,653 (wt), 8,889,937 (nrpd1) and 3,664,258 ( $r d r 2$ ) that matched tRNA, rRNA, snRNA or snoRNAs. Libraries of small RNAs were constructed from total RNA isolated from mixed stage inflorescence tissues of wild type (WT) Arabidopsis Col-0, mutants $n r p d 1$ and $r d r 2$ using TRIzol reagent (Invitrogen, Carlsbad, CA, USA). Total RNA $(200 \mu \mathrm{g})$ for each sample was used to construct the small RNA libraries as described previously [60] but with different adapters. The RNA oligos (Dharmacon, Lafayette, Colorado, USA) used for small RNA ligations were as follows: 5' RNA Adapter (5'OH-GUUCAGAGUUCUACAGUCCGACGAUC-OH 3') and 3' RNA Adapter: (5' pUCGUAUGCCGUCUUCUGCUUGUidt 3'; p, phosphate; idT, inverted deoxythymidine). Libraries of small
RNAs were sequenced using Illumina's (San Diego, CA, USA) sequencing by synthesis technology at the Delaware Biotechnology Institute. This generated 12,043,425 total reads from wt Col-0, 13,580,575 from mutant $n r p d 1$ and 9,001,733 from mutant $r d r 2$.

Adapter sequences were removed using a Perl script, generating small RNA sequences plus abundances. The data were matched to the Arabidopsis genome (TAIR v9). Of the $12,043,425$ total reads from wildtype Col-0 (WT), 13,580,575 from mutant $n r p d 1$ and 9,001,733 from mutant $r d r 2,8,577,577$ (WT), 2,858,557 (nrpd1) and 4,322,052 ( $r d r 2)$ reads matched the genome, excluding 1,709,653 (WT), 8,889,937 (nrpd1) and 3,664,258 $(r d r 2)$ that matched tRNA, rRNA, snRNA or snoRNAs. The small RNA sequence data are available from NCBI's Gene Expression Omnibus (GEO) and are accessible via GEO Series accession number GSE34207. Accession numbers for the separate libraries are GSM844489 (rdr2_sRNA); GSM844490 (nrpd1 rdr2_sRNA); and GSM844491 [WT (Col-0)_sRNA].

\section{Semi-quantitative RT-PCR}

Total RNA was extracted from 3 week old seedlings (100 mg) or mixed floral inflorescences $(100 \mathrm{mg})$ by using TRIzol $^{\circledR}$ Reagent (Invitrogen, Lofer, Austria) according to the manufacturer's instructions. One $\mu \mathrm{g}$ of total RNA was used for reverse transcription using RevertAid ${ }^{\mathrm{TM}} \mathrm{H}$ Minus First Strand cDNA Synthesis Kit (Fermantas, St. Leon-Rot, Germany) following the manufacturer's instructions. One $\mu \mathrm{L}$ cDNA was used for semi-quantitative reverse transcriptase-mediated (RT) PCR analysis. The PCR conditions were $95^{\circ} \mathrm{C}$ for 5 min followed by 23 (actin), 25 (MPK3), 40 (CRP genes) amplification cycles $\left(95^{\circ} \mathrm{C}\right.$ for $30 \mathrm{~s}, 55^{\circ} \mathrm{C}$ for $30 \mathrm{~s}$, and $72^{\circ} \mathrm{C}$ for $\left.1 \mathrm{~min}\right)$. Actin (At3g18780) was used a constitutively expressed internal control. Primers used for RT-PCR are listed in Additional file 4: Table S3.

\section{GUS assays and GFP visualization}

Transgenic plants transformed with the three constructs described above were used to detect synergid cell-specific expression of GUS and GFP reporter genes. GUS assays were performed as described previously [28]. Briefly, ovules were dissected from early opened flowers (emasculated $24 \mathrm{hr}$ before) in a small petri dish containing GUS staining solution $(50 \mathrm{mM}$ sodium phosphate buffer $\mathrm{pH}$ 7.0, $10 \mathrm{mM}$ EDTA, $0.1 \%$ Triton X-100, $2 \mathrm{mM}$ potassium ferrocyanide, $2 \mathrm{mM}$ potassium ferricyanide, and $1 \mathrm{mg} / \mathrm{ml}$ $\mathrm{X}$-Gluc) on ice. The ovules were incubated at $37^{\circ} \mathrm{C}$ for 30 min, cleared with $20 \%$ methanol $/ 4 \%$ concentrated $\mathrm{HCl}$ solution at $55^{\circ} \mathrm{C}$ for $15 \mathrm{~min}$, and then transferred into a solution containing $60 \%$ ethanol/1.8 M NaOH at $25^{\circ} \mathrm{C}$ for $10 \mathrm{~min}$. Samples were washed with $30 \%$ ethanol and $10 \%$ ethanol and mounted onto slides with a $50 \%$ glycerol 
solution. Images were acquired using a Leica stereofluorescence microscope MZ16FA equipped with a Leica GFP2 filter set and a Leica DFC 300FX camera (Leica $\mathrm{GmbH}$, Germany).

To visualize GFP, ovules were dissected from early opened flowers (before fertilization), and localization of the GFP signal was viewed by using Leica stereofluorescence microscope MZFLIII.

\section{Tissue Embedding and Laser-Assisted Microdissection (LAM)}

Flowers were emasculated and harvested 48-72 hrs thereafter. The tissue was fixed in EtOH:Acetic Acid 3:1 $(\mathrm{v} / \mathrm{v})$ under vacuum for $2 \mathrm{x} 15 \mathrm{~min}$ at $4^{\circ} \mathrm{C}$, according to Kerk and coworkers [61], then left in the fixative overnight at $4^{\circ} \mathrm{C}$. The tissue was embedded in Paraplast ${ }^{\circledR}$ Regular embedding media (Sigma-Aldrich, Vienna, Austria) using an automated protocol.

In the automated procedure, the fixed tissue was embedded using the automated Sakura Tissue-Tek ${ }^{\circledR}$ VIP ${ }^{\text {TM }}$ embedding machine (Sakura Finetek Europe B.V., Alphen aan den Rijn, The Netherlands) with the following parameters: $1 \mathrm{hr} 70 \% \mathrm{EtOH}$ at $37^{\circ} \mathrm{C}, 1 \mathrm{x} 1 \mathrm{~h} 80 \% \mathrm{EtOH}, 2 \mathrm{x}$ 1 h 96 \% EtOH, 2x 1 h 100 \% EtOH, 2x 1 h 100 \% Xylol, all at $40^{\circ} \mathrm{C}$, and then $4 \times 1 \mathrm{~h}$ Paraplast ${ }^{\circledR}$ Regular embedding media (Sigma-Aldrich, Vienna, Austria) at $60^{\circ} \mathrm{C}$. Flowers were poured into paraffin-blocks, cooled and then kept at $4^{\circ} \mathrm{C}$ until use.

For microdissection, the embedded flowers were sectioned on the Leica microtome RM2145 (Leica Microsystems GmbH, Wetzlar, Germany) to $8 \mu \mathrm{m}$ thickness and mounted onto RNase-free membrane slides (Molecular Machines \& Industries [MMI] AG, Glattbrugg, Switzerland) with the use of RNAse free miliQ water. Slides were dried overnight on a heating table at $42^{\circ} \mathrm{C}$ and processed the following day. Microdissection was performed with a CellCut Plus instrument (MMI AG, Glattbrugg, Switzerland), which makes use of a solid state UV-A laser (wavelength approx. $350 \mathrm{~nm}$ ) to cut the tissue. Each slide was deparaffinized by processing in $100 \%$ Xylene for 2x 10 minutes at room temperature. Slides were air-dried for $10 \mathrm{~min}$. and immediately used for laser microdissection. Synergids cells were harvested using MMI isolation caps, with an average of 110 cells isolated per cap. Due to the cytology of the egg apparatus, it was not possible to isolate the synergids cells without including a small basal part of the egg cell in the same section [43]. However care was taken to avoid contamination of the sample with egg cell nuclei. Therefore, for DNA methylation studies the sample can be considered as purely synergid cells.

Detection of CRP4-GFP fusion proteins by Western blotting Total proteins were extracted from 3 week old seedlings grown on solid Murashige and Skoog (MS) medium.
Approximately $50 \mathrm{mg}$ seedlings were harvested, ground in liquid nitrogen and resuspended using $100 \mu \mathrm{l}$ extraction buffer (50 mM HEPES-KOH pH 7.9, $400 \mathrm{mM} \mathrm{KCl}$, $2.5 \mathrm{mM} \mathrm{MgCl}_{2}, 1 \mathrm{mM}$ EDTA, $1 \mathrm{mM}$ DTT, $0.1 \%$ Triton $\mathrm{X}$-100) supplemented with EDTA-free protease inhibitor cocktail (Roche, Vienna, Austria). After centrifuging 15 min at $4^{\circ} \mathrm{C}$, the supernatant was mixed with the same volume of extraction buffer without $\mathrm{KCl}$. Proteins were separated using $10 \%$ SDS-PAGE and transferred to a PVDF membrane (Millipore, Vienna, Austria). Membranes were probed either with mouse monoclonal antibodies against GFP (1:1,000) (Roche, Vienna, Austria) or tubulin (1:1,000) (Sigma-Aldrich, Vienna, Austria), followed by horseradish peroxidase conjugated goat antimouse secondary antibody (1:10,000, Biorad, Vienna, Austria). The blots were developed using an enhanced chemoluminescence ECL kit (Thermo Scientific, Vienna, Austria), and exposed to CL-XP X-ray film (Thermo Scientific, Vienna, Austria).

\section{Treatment with flg22 and heat stress}

Dried seeds were sterilised with $70 \%$ ethanol/ $0.05 \%$ tritonX-100 and sown on solid MS medium. One week after germinating, small seedlings were transferred to liquid MS medium supplied with $1 \mu \mathrm{M}$ flg22 peptide (kindly provided by Elke Logemann and Imre Somssich, Max Planck Institute for Plant Breeding Research, Cologne) (4 seedlings per $400 \mu \mathrm{l}$ of medium in wells of 24 well plates). Batches of seedlings were collected after $10 \mathrm{~min}, 20 \mathrm{~min}$, and $30 \mathrm{~min}$ of flg 22 treatment followed by semi-quantitative RT-PCR to detect expression of the CRP4 gene and MPK3.

For heat stress, approximately one week-old seedlings were transferred into liquid MS medium and incubated at $4^{\circ} \mathrm{C}$ for $24 \mathrm{hr}$, and different batches were then incubated for $4 \mathrm{hrs}, 8 \mathrm{hrs}$, and $24 \mathrm{hrs}$, respectively, at $37^{\circ} \mathrm{C}$. Stressed seedlings were allowed to recover at $21^{\circ} \mathrm{C}$ for 3 days, and then used for semi-quantitative RT-PCR to detect expression of the CRP4 gene and Onsen retrotransposon [19].

\section{Accession numbers}

Accession numbers for the single SAT5 monomers containing CRP genes or pseudogenes shown in Table 1 are as follows: chr2 SAT5 fragment containing At2g18042 pseudogene [EMBL:HE610172]; chromosome 3 SAT5 fragment containing At3g42565 gene [EMBL:HE610173]; chromosome 4 SAT5 fragment containing At4g09545 gene [EMBL:HE610174]; chromosome 5 SAT5 fragment containing At5g60978 pseudogene [EMBL:HE610175]. The small RNA sequence data are available from NCBI's Gene Expression Omnibus (GEO) and are accessible via GEO Series accession number GSE34207. 


\section{Additional files} Additional file 1: Figure S1. Differentially accumulating fragments in
MSAP analysis.

Additional file 2: Figure S2. Sequence alignments.

Additional file 3: Table S1. Methylation status of members of the CRP3600 subgroup.

Additional file 4: Table S3. Primers.

\section{Abbreviations}

AGl: Arabidopsis Genome Initiative; ATSAT5 (SAT5): Arabidopsis thaliana satellite sequence on chromosome 5; CMT3: Chromomethylase 3; CRP: Cysteine-rich peptide; CRP4: At4g09545; CRP5a: At5g42895; CRP5b: At5g44495; DCL3: Dicer-like3; DDM1: Decrease in dna methylation1; DMS4: Defective in meristem silencing 4; DRM: Domains rearranged methyltransferase; ECA1: Early culture abundant; EGFP: Enhanced GFP; GFP: Green fluorescent protein; GUS: ß-glucuronidase; LAM: Laser-assisted microdissection; MSAP: Methylation-sensitive amplification polymorphism; MET1: Methyltransferase 1; NRPD1: Largest subunit of nuclear RNA polymerase IV (PoI IV); NRPE1: Largest subunit of nuclear RNA polymerase $\mathrm{V}$ (Pol V); RDR2: RNA-DEPENDENT RNA POLYMERASE 2; RDR6: RNA-DEPENDENT RNA POLYMERASE 6; SAT5: Short name for ATSAT5; TAIR: The Arabidopsis Information Resource.

\section{Acknowledgements}

Work in the Matzke lab is supported by the Austrian Academy of Sciences and a grant from the Austrian Fonds zur Förderung der wissenschaftlichen Forschung (grant no. SFB F4306-B09). Work in the Meyers lab is supported by the US NSF Plant Genome Research Program award \#0701745. Work in the Grossniklaus lab is supported by the University of Zürich and the Swiss National Science Foundation. We thank Zdravko Lorkovic for critical reading of the manuscript and Johannes van der Winden for technical and editorial assistance.

\section{Author details}

${ }^{1}$ Gregor Mendel Institute of Molecular Plant Biology, Austrian Academy of Sciences, Vienna, Austria. ${ }^{2}$ Institute of Plant Biology and Zürich-Basel Plant Science Center, University of Zürich, Zürich, Switzerland. ${ }^{3}$ Department of Plant and Soil Sciences, and Delaware Biotechnology Institute, University of Delaware, Newark, USA. ${ }^{4}$ Institute of Bioorganic Chemistry, Polish Academy of Sciences, Poznan, Poland. ${ }^{5}$ Epigenetics Laboratory, Queensland Institute of Medical Research, Herston, Brisbane, Queensland, Australia.

\section{Authors' contributions}

WY, AT, AM and MM designed the study; WY, AT, MS, LD SS, BM generated and interpreted data; MWS and UG helped with the LAM studies; WY, AT, LD, UG, MS, MS, SS, BM, AM, MM interpreted data; WY, AT, LD, MS, UG, SS, BM and MM prepared the paper. All authors read and approved the final manuscript.

Received: 16 November 2011 Accepted: 19 April 2012 Published: 19 April 2012

\section{References}

1. Haag JR, Pikaard CS: Multisubunit RNA polymerases IV and V: purveyors of non-coding RNA for plant gene silencing. Nat Rev Mol Cell Biol 2011, 12:483-492.

2. Matzke M, Kanno T, Daxinger L, Huettel B, Matzke AJM: RNA-mediated chromatin-based silencing in plants. Curr Opin Cell Biol 2009, 21:367-376.

3. Wierzbicki AT, Ream TS, Haag JR, Pikaard CS: RNA polymerase V transcription guides ARGONAUTE4 to chromatin. Nat Genet 2009, 41:630-634.

4. Wassenegger M: RNA-directed DNA methylation. Plant Mol Biol 2000, 43:203-220

5. Cao X, Aufsatz W, Zilberman D, Mette MF, Huang MS, Matzke M, Jacobsen SE: Role of the DRM and CMT3 methyltransferases in RNA-directed DNA methylation. Curr Biol 2003, 13:2212-2217.

6. Naumann U, Daxinger L, Kanno T, Eun C, Long Q, Lorkovic ZJ, Matzke M, Matzke AJM: Genetic evidence that DNA methyltransferase DRM2 has a direct catalytic role in RNA-directed DNA methylation in Arabidopsis thaliana. Genetics 2011, 187:977-979.
7. Law JA, Jacobsen SE: Establishing, maintaining and modifying DNA methylation patterns in plants and animals. Nat Rev Genet 2010, 11:204-220.

8. Lister R, O'Malley RC, Tonti-Filippini J, Gregory BD, Berry CC, Millar AH, Ecker JR: Highly integrated single-base resolution maps of the epigenome in Arabidopsis. Cell 2008, 133:523-536.

9. Cokus SJ, Feng S, Zhang X, Chen Z, Merriman B, Haudenschild CD, Pradhan S, Nelson SF, Pellegrini M, Jacobsen SE: Shotgun bisulphite sequencing of the Arabidopsis genome reveals DNA methylation patterning. Nature 2008, 452:215-219.

10. Henderson IR, Jacobsen SE: Tandem repeats upstream of the Arabidopsis endogene $S D$ recruit non-CG DNA methylation and initiate siRNA spreading. Genes Dev 2008, 22:1597-1606.

11. Weil C, Martienssen R: Epigenetic interactions between transposons and genes: lessons from plants. Curr Opin Genet Dev 2008, 18:188-192.

12. Chan SW, Zhang $X$, Bernatavichute $Y$, Jacobsen SE: Two-step recruitment of RNA-directed DNA methylation to tandem repeats. PLoS Bio/ 2006, 4:e363.

13. Saze $H$, Kakutani T: Differentiation of epigenetic modifications between transposons and genes. Curr Opin Plant Biol 2011, 14:81-87.

14. Pelizzola M, Ecker J: The DNA methylome FEBS. Lett 2011, 585:1994-2000.

15. Rigal M, Mathieu O: A "mille-feuille" of silencing: epigenetic control of transposable elements. Biochim Biophys Acta 2011, 1809:452-458.

16. Zilberman D, Gehring M, Tran RK, Ballinger T, Henikoff S: Genome-wide analysis of Arabidopsis thaliana DNA methylation uncovers an interdependence between methylation and transcription. Nat Genet 2007, 39:61-69.

17. Chodavarapu RK, Feng S, Bernatavichute YV, Chen PY, Stroud H, Yu Y, Hetzel JA, Kuo F, Kim J, Cokus SJ, Casero D, Bernal M, Huijser P, Clark AT, Kramer U, Merchant SS, Zhang X, Jacobsen SE, Pelligrini M: Relationship between nucleosome positioning and DNA methylation. Nature 2010, 466:388-392.

18. Aceituno FF, Moseyko N, Rhee SY, Gutiérrez RA: The rules of gene expression in plants: organ identify and gene body methylation are key factors for regulation of gene expression in Arabidopsis thaliana. BMC Genomics 2008, 9:438.

19. Ito H, Gaubert H, Bucher E, Mirouze M, Vaillant I, Paszkowski J: An siRNA pathway prevents transgenerational retrotransposition in plants subjected to stress. Nature 2011, 472:115-119.

20. Inagaki S, Kakutani T: Control of genic DNA methylation in Arabidopsis. J Plant Res 2010, 123:299-302.

21. Vos P, Hogers R, Bleeker M, Reijans M, van de Lee T, Hornes M, Frijters A, Pot J, Peleman J, Kulper M, Zabeau M: AFLP: a new technique for DNA fingerprinting. Nucl Acids Res 1995, 23:4407-4414.

22. Sasaki T, Fujimoto R, Kishitani S, Nishio T: Analysis of target sequences of DDM1 in Brassica rapa by MSAP. Plant Cell Rep 2011, 30:81-88.

23. Kanno T, Huettel B, Mette MF, Aufsatz W, Jaligot E, Daxinger L, Kreil DP, Matzke M, Matzke AJM: Atypical RNA polymerase subunits required for RNA-directed DNA methylation. Nat Genet 2005, 37:761-765.

24. Kanno T, Bucher E, Daxinger L, Huettel B, Böhmdorfer G, Gregor W, Kreil DP, Matzke M, Matzke AJM: A structural maintenance of chromosomes hinge domain-containing protein is required for RNA-directed DNA methylation. Nat Genet 2008, 40:670-675.

25. Genetic Information Research Institute: ATSAT5: A satellite-like sequence from chromosome 5 - a consensus. Repbase Reports 2006, 6:50.

26. Silverstein KA, Moskal WA Jr, Wu HC, Underwood BA, Graham MA, Town CD, VandenBosch KA: Small cysteine-rich peptides resembling antimicrobial peptides have been under-predicted in plants. Plant J 2007, 51:262-280.

27. Jones-Rhoades MW, Borevitz JO, Preuss D: Genome-wide expression profiling of the Arabidopsi female gametophyte identifies families of small, secreted proteins. PLoS Genetics 2007, 3:1848-1861.

28. Pulido A, Bakos F, Devic M, Barnabás B, Olmedilla A: HvPG and ECA: two genes activated transcriptionally in the transition of barley microspores from the gametophytic to the embryogenic pathway. Plant Cell Rep 2009, 28:551-559.

29. Manners JM: Hidden weapons of microbial destruction in plant genomes. Genome Biol 2007, 8:225.

30. Meindl T, Boller T, Felix G: The bacterial elicitor flagellin activates its receptor in tomato cells according to the address-message concept. Plant Cell 2000, 12:1783-1794.

31. Asai T, Tena G, Plotnikova J, Willmann MR, Chiu WL, et al: MAP kinase signaling cascade in Arabidopsis innate immunity. Nature 2002, 415:977-983.

32. Teixeira FK, Colot V: Gene body DNA methylation in plants: a means to an end or an end to a means? EMBO J 2009, 28:997-998.

33. Huettel B, Kanno T, Daxinger L, Aufsatz W, Matzke AJM, Matzke M: Endogenous targets of RNA-directed DNA methylation and Pol IV in Arabidopsis. EMBO J 2006, 25:2828-2836. 
34. Okuda S, Tsutsui H, Shiina K, Sprunck S, Takeuchi H, Yui R, Kasahara RD, Hamamura Y, Mizukami A, Susaki D, Kawano N, Sakakibara T, Namiki S, Itoh K, Otsuka K, Matsuzaki M, Nozaki H, Kuroiwa T, Nakano A, Kanaoka MM, Dresselhaus T, Sasaki N, Hihashiyama T: Defensin-like polypeptide LUREs are pollen tube attractants secreted from synergid cells. Nature 2009, 458:357-361.

35. Dresselhaus T, Márton ML: Micropylar pollen tube guidance and burst: adapted from defense mechanisms? Curr Opin Plant Biol 2009, 12:773-780.

36. Graham MA, Silverstein KA, VandenBosch KA: Defensin-like genes: genomic perspectives on a diverse superfamily in plants. Crop Sci 2008, 48:S3-S11.

37. Wheeler II, Irving HR: Evolutionary advantages of secreted peptide signaling molecules in plants. Functional Plant Biology 2010, 37:382-394.

38. Marshall E, Costa LM, Gutierrez-Marcos J: Cysteine-rich peptides (CRPs) mediate diverse aspects of cell-to-cell communication in plant reproduction and development. J Ex Bot 2011, 62:1677-1686.

39. Grossniklaus U: Plant germline development: a tale of cross-talk, signaling and cellular interactions. Sex Plant Reprod 2011, 24:91-95.

40. Miura A, Nakamura M, Inagaki S, Kobayashi A, Saze H, Kakutani T: An Arabidopsis jmjC domain protein protects transcribed genes from DNA methylation at CHG sites. EMBO J 2009, 28:1078-1086.

41. Bauer MJ, Fischer RL: Genome demethylation and imprinting in the endosperm. Curr Opin Plant Biol 2011, 14:162-167.

42. Raissig MT, Baroux C, Grossniklaus U: Regulation and flexibility of genomic imprinting during seed development. Plant Cell 2011, 23:16-26.

43. Wuest SE, Vijverberg K, Schmidt A, Weiss M, Gheyselinck J, Lohr M, Wellmer F, Rahnenführer J, von Mering C, Grossniklaus U: Arabidopsis female gametophyte gene expression map reveals similarities between plant and animal gametes. Curr Biol 2010, 20:506-512.

44. Punwani JA, Rabiger DS, Drews GN: MYB98 positively regulates a battery of synergid-expressed genes encoding filiform apparatus localized proteins. Plant Cell 2007, 19:2557-2568.

45. González RM, Ricardi MM, lusem ND: Atypical epigenetic mark in an atypical location: cytosine methylation at asymmetric (CNN) sites within the body of a non-repetitive tomato gene. BMC Plant Biol 2011, 11:94.

46. Lister R, Pelizzola M, Kida YS, Hawkins RD, Nery JR, Hon G, Antosiewicz-Bourget J, O'Malley R, Castanon R, Klugman S, Downes M, Yu R, Stewart R, Ren B, Thomson JA, Evans RM, Ecker JR: Hotspots of aberrant epigenomic reprogramming in human induced pluripotent stem cells. Nature 2011, 471:68-73.

47. Vaknin K, Goren A, Ast G: TEs or not TEs? That is the evolutionary question. J Biol 2009, 8:83.

48. Takayama S, Shimosato H, Shiba H, Funato M, Che FS, Watanabe M, Iwano M, Isogai A: Direct ligand-receptor complex interaction controls Brassica self-incompatibility. Nature 2001, 413:534-538.

49. Xie Z, Johansen LK, Gustafson AM, Kasschau KD, Lellis AD, Zilberman D, Jacobsen SE, Carrington JC: Genetic and functional diversification of small RNA pathways in plants. PLoS Biol 2004, 2:E104.

50. Smith L, Pontes O, Searle I, Yelina N, Yousafzai FK, Herr AJ, Pikaard CS, Baulcombe DC: An SNF2 protein associated with nuclear RNA silencing and the spread of a silencing signal between cells in Arabidopsis. Plant Cell 2007, 19:1507-1521.

51. Kanno T, Bucher E, Daxinger L, Huettel B, Kreil DP, Breinig F, Lind M, Schmitt M, Simon SA, Gurazada SG, Meyers BC, Lorkovic ZJ, Matzke AJM, Matzke M: RNA-directed DNA methylation and plant development require an IWR1-type transcription factor. EMBO Rep 2010, 11:65-71.

52. Elmayan T, Balzergue S, Béon F, Bourdon V, Daubremet J, Guénet $Y$, Mourrain $P$, Palauqui JC, Vernhettes S, Vialle T, Wostrikoff K, Vaucheret H: Arabidopsis mutants impaired in cosuppression. Plant Cell 1998, 10:1747-1758.

53. Hajdukiewicz P, Svab Z, Maliga P: The small versatile pPZP family of Agrobacterium binary vectors for plant transformation. Plant Mol Biol 1994, 25:989-994.

54. Pietrzak M, Shillito RD, Hohn T, Potrykus I: Expression in plants of two bacterial antibiotic resistance genes after protoplast transformation with a new plant expression vector. Nucl Acids Res 1986, 14:5857-5868.

55. Töpfer R, Schell J, Steinbiss HH: Versatile cloning vectors for transient gene expression and direct gene transfer to plants. Nucl Acids Res 1988, 16:8725.

56. Matzke AJM, Matzke MA: A set of novel Ti plasmid-derived vectors for the production of transgenic plants. Plant Mol Biol 1986, 7:357-365.

57. Clough SJ, Bent AF: Floral dip: a simplified method for Agrobacterium-mediated transformation of Arabidopsis thaliana. Plant J 1998, 16:735-743.
58. Daxinger L, Kanno T, Bucher E, van der Winden J, Naumann U, Matzke AJM Matzke M: A stepwise pathway for biogenesis of 24-nt secondary siRNAs and spreading of DNA methylation. EMBO J 2009, 28:48-57.

59. Reinders J, Delucinge Vivier C, Theiler G, Chollet D, Descombes P, Paszkowski J: Genome-wide, high-resolution DNA methylation profiling using bisulfite-mediated cytosine conversion. Genome Res 2008, 18:469-476.

60. Lu C, Meyers BC, Green PJ: Construction of small RNA cDNA libraries for deep sequencing. In Methods in Molecular Biology. Volume 43. Totowa New Jersey: Humana Press: 110-117

61. Kerk NM, Ceserani T, Tausta SL, Sussex IM, Nelson TM: Laser capture microdissection of cells from plant tissues. Plant Physiol 2003, 132:27-35.

doi:10.1186/1471-2229-12-51

Cite this article as: You et al:: Atypical DNA methylation of genes encoding cysteine-rich peptides in Arabidopsis thaliana. BMC Plant Biology 2012 12:51.

\section{Submit your next manuscript to BioMed Central and take full advantage of:}

- Convenient online submission

- Thorough peer review

- No space constraints or color figure charges

- Immediate publication on acceptance

- Inclusion in PubMed, CAS, Scopus and Google Scholar

- Research which is freely available for redistribution 